\title{
Laboratory Apparatus for Providing Diel Temperature Regimes for Aquatic Animals ${ }^{1}$
}

\author{
Wayne A. Wurtsbaugh ${ }^{2}$ and Gerald E. Davis \\ Department of Fisheries and Wildlife \\ Oregon State University, Corvallis, Oregon 97331
}

In studies of the effects of elevated temperature on aquatic organisms, little emphasis has been placed on modeling the fluctuating temperatures to which organisms are exposed in nature. To some extent this may be related to problems of design and maintenance of apparatus for fluctuating temperature control. The complexity of apparatus used to provide cycled temperatures has ranged from manually controlled valves for introducing water of different temperatures into aquariums (Kelso 1972), to a complex and expensive feedback system, regulated by rotating cams, that controls the temperature of influent water (Honeywell Cam Programmer Thermometers, Fort Washington, Pennsylvania). To facilitate studies of the effects of temperature fluctuation on the growth of fishes, we constructed an apparatus that was easy to use and of moderate cost. DeHart (1975) used apparatus of similar design but greater complexity to study the thermal resistance of fishes to fluctuating temperatures.

In our apparatus (Fig. 1) water in a series of plywood headboxes (each 35 liters) is kept at different predetermined constant temperatures with stainless steel immersion heaters (1,000 W; VWR Scientific, Seattle, Washington), which are controlled by monitor relays (Lab Apparatus Co., Cleveland, Ohio). If a comparison of the effects at constant temperatures with those at fluctuating temperatures is desired, water can be taken directly from these headboxes; additional headboxes can be included to provide water of intermediate temperature. Water flow to tanks with fluctuating temperatures is controlled by plastic solenoid valves (Asco Valves, Model 8206; Automatic Switch Co., Florham Park, New Jersey) regulated by electrical time switches (W.W. Grainger, Inc., Portland, Oregon). The solenoid valves can be adjusted to vary the rate of water flow.

To provide a diel temperature cycle, the operator sets one timer to allow the inflow of water from a "warm"

\footnotetext{
${ }^{1}$ Technical Paper 4044, Oregon Agricultural Experiment Station, Oregon State University.

${ }^{2}$ Present address: Lake County Mosquito Abatement District, 410 Esplanade, Lakeport, Calif. 95453.
}

headbox to the tanks for $18 \mathrm{~h}$, beginning at $0700 \mathrm{~h}$ each day, and another timer to allow inflow of "cool" water from another headbox to the tanks for $18 \mathrm{~h}$, beginning at $1900 \mathrm{~h}$ each day. Thus the flows of warm and cool water overlap, and temperature changes in the tanks are not abrupt. The temperature extremes of the diel cycle closely approximate the water temperatures in the warm and cool headboxes. In our system, water was mixed in a funnel and then distributed to four insulated tanks by a manifold of polyvinyl chloride pipe. Water flow to each tank was regulated by adjustable glass outlet tubes. A water-overflow pipe in the manifold maintained a constant head pressure, regardless of changes in flow from the two solenoid valves. An air stone in each tank prevented temperature stratification and ensured high oxygen levels. A thermograph recorded temperatures from the pooled outflow water of the four tanks.

The rate of temperature change in the system is determined by the rate of water flow to the tanks and the size of tanks used. Studies of the effects of fluctuating temperatures on the growth of steelhead trout, Salmo gairdneri (Wurtsbaugh 1973), showed that 4 or $8^{\circ} \mathrm{C}$ diel fluctuations were provided by flow rates of $140 \mathrm{ml} / \mathrm{min}$ to 10-liter tanks. Plots of experimental temperatures against time indicated that the diel temperature fluctuations were approximately sigmoid and that $11 \mathrm{~h}$ were required for temperature changes from one extreme to the other. Smoother temperature curves can be obtained if more solenoids and timers are used (DeHart 1975), but for most experiments two solenoids adequately reproduce a normal diel fluctuation.

Larger temperature fluctuations than those we employed can be attained, but the heating capacity of the immersion heaters must not be exceeded. When temperature fluctuations are large, heat loss and gain by the tubing and aquariums complicates temperature control; insulating exposed surfaces reduces this effect. The apparatus should be housed in a constant temperature room to avoid interference from changes in the ambient air temperature. The approximate cost of the heating and temperature control apparatus was $\$ 180$ (January 1973). 


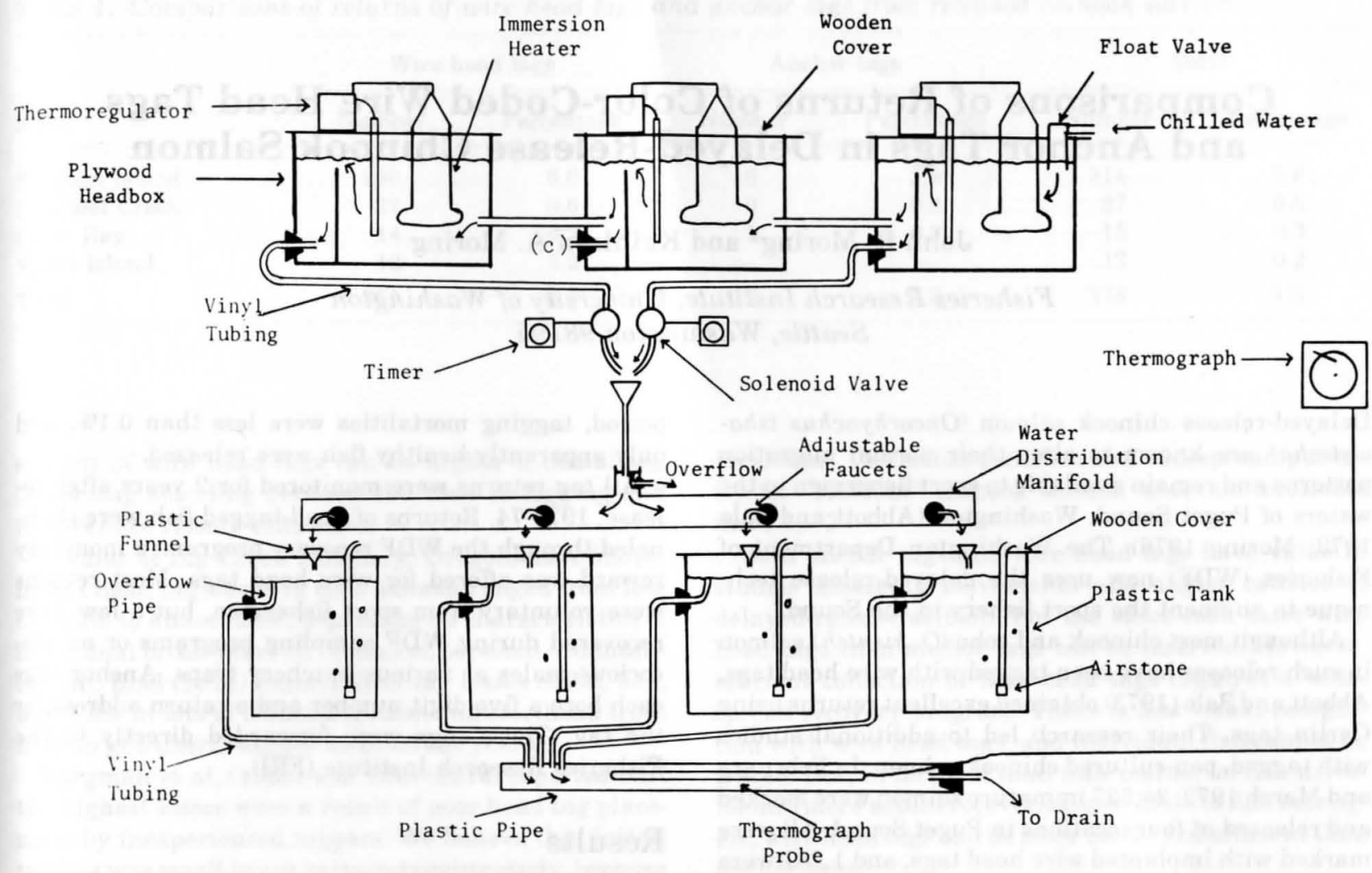

Fig. 1. Diagram of temperature control apparatus. Water from an intermediate headbox (c) may be used for constant temperature treatments.

\section{Acknowledgments}

We thank Douglas DeHart for suggesting the use of plastic solenoid valves and C. E. Bond and J. D. McIntyre for reviewing the manuscript.

\section{References}

DeHart, D. 1975. Resistance of three freshwater fishes to fluc- tuating thermal environments. M.S. thesis. Oregon State University, Corvallis. $63 \mathrm{pp}$.

Kelso, J. 1972. Conversion, maintenance, and assimilation for walleye, Stizostedion vitreum vitreum, as affected by size, diet, and temperature. J. Fish. Res. Board Can. 29:11811192.

Wurtsbaugh, W. 1973. Effects of temperature, ration and size on the growth of juvenile steelhead trout, Salmo gairdneri. M.S. thesis. Oregon State University, Corvallis. 69 pp. 